\title{
Médiévales
}

Langues, Textes, Histoire

47 | automne 2004

Îles du Moyen Âge

\section{Food \& History, Revue semestrielle publiée par l'Institut européen d'histoire de l'alimentation}

Volume 1, $\mathrm{n}^{\circ}$ 1, 2003, Brepols, 274 p.

\section{Bruno Laurioux}

\section{OpenEdition}

Journals

Édition électronique

URL : https://journals.openedition.org/medievales/1086

DOI : 10.4000/medievales. 1086

ISSN : 1777-5892

\section{Éditeur}

Presses universitaires de Vincennes

\section{Édition imprimée}

Date de publication : 1 décembre 2004

Pagination : 184-185

ISBN : 2-84292-157-7

ISSN : 0751-2708

\section{Référence électronique}

Bruno Laurioux, «Food \& History, Revue semestrielle publiée par l'Institut européen d'histoire de

l'alimentation », Médiévales [En ligne], 47 | automne 2004, mis en ligne le 13 mars 2006, consulté le 24 avril 2022. URL : http://journals.openedition.org/medievales/1086 ; DOI : https://doi.org/10.4000/ medievales.1086

Ce document a été généré automatiquement le 24 avril 2022

Tous droits réservés 


\title{
Food \& History, Revue semestrielle publiée par l'Institut européen d'histoire de l'alimentation
}

\author{
Volume 1, $\mathrm{n}^{\circ} 1,2003$, Brepols, $274 \mathrm{p}$.
}

\section{Bruno Laurioux}

1 Médiévales, qui dès les débuts de son existence a fait une large place aux nourritures, ne pouvait que se réjouir de la naissance d'une revue entièrement consacrée à l'histoire de l'alimentation. Publiée par un jeune Institut qui se donne pour objectif d'impulser et de coordonner les recherches en la matière, Food \& History se veut donc résolument multilingue et pluripériodique. Avec cinq articles de fond sur dix, la part qu'occupe le Moyen Âge dans ce premier numéro est dominante - et cela reflète assez le dynamisme des médiévistes à l'intérieur d'un domaine toujours en pleine expansion.

2 La diversité des thèmes traités illustre le statut de carrefour de l'alimentation, phénomène total qui touche au culturel et à l'économique comme au social et au biologique. Après deux décennies essentiellement consacrées aux livres de cuisine, les historiens se tournent aujourd'hui vers d'autres sources, les menus par exemple, davantage en prise sur les pratiques et dont Gilly Lehmann ( $«$ The Late-Medieval Menu in England - a Reappraisal», p. 49-83) décrypte les subtiles et évolutives logiques, corrigeant sur de nombreux points les analyses du regretté Jean-Louis Flandrin. Des documents plus connus font l'objet de nouvelles interrogations: ainsi, reprenant les règles et coutumiers monastiques du très haut Moyen Âge, notamment hispaniques, Antoni Riera Melis ( $«$ La faim comme outil expiatoire. Les restrictions alimentaires édictées par certaines règles monastiques aux $\mathrm{VI}^{\mathrm{e}}$ et $\mathrm{VII}^{\mathrm{e}}$ siècles", p. 33-48) est en mesure d'aller plus loin que les habituelles évocations sur le carême et de montrer comment les drastiques restrictions alimentaires imposées aux auteurs de péchés graves n'ont pas peu contribué à l'annihilation physique et sociale des moines excommuniés - et il est difficile ici de ne pas faire un parallèle avec ce qu'Aline Rousselle a écrit sur la chasteté/sexualité des moines de la même époque. 
3 Une autre tendance récente est le retour à une histoire économique, attentive aux processus de fabrication et de distribution, ici représentée par une très utile mise au point sur le sucre sicilien que Mohamed Ouerfelli a tirée de l'analyse minutieuse des actes notariés du Xve siècle ( Production et commerce du sucre en Sicile au $\mathrm{xv}^{\mathrm{e}}$ siècle : la participation étrangère », p. 103-122) ; c'est une pierre de touche pour l'histoire comparée - sur tout l'espace méditerranéen et sur la longue durée du Moyen Âge - d'un aliment qui, à bien des égards, apparaît comme un marqueur.

4 Plus attendus sont les articles relevant de ce que l'on pourrait appeler l'histoire culturelle en général. Ainsi Johanna Maria Van Winter, à partir de sources aussi variées que les poèmes sur les manières de table, les chroniqueurs de la cour bourguignonne ou les comptes de confréries, reprend-elle le dossier de la sociabilité à table («Festive Meals in the late Middle Ages: An Essay on Dining as a Means of Communication », p. 95-102). Quant à Barbara Santich, elle a le mérite de recenser les textes littéraires développant le thème bien connu du « cœur mangé » (« Revenge, Cannibalism and SelfDenial », p. 85-94).

5 À côté d'articles de fond témoignant de nouvelles recherches, Food \& History se donne pour tâche de republier des « classiques " (ici le manifeste fameux, quoique discutable, de Fernand Braudel sur "Alimentation et catégories de l'histoire »). Elle publie aussi des comptes rendus et des revues critiques: Massimo Montanari revient ainsi sur un thème - celui des rapports complexes entre l'anorexie et la sainteté féminine - qui a beaucoup passionné les médiévistes dans les années quatre-vingts et le début des années quatre-vingt-dix du $\mathrm{xx}^{\mathrm{e}}$ siècle.

6 Souhaitons donc longue vie à cette revue dont la facture est de surcroît fort agréable. Débarrassée des quelques scories qu'impliquent de multiples traductions, elle est appelée à devenir un instrument de référence pour tous ceux - et ils sont de plus en plus nombreux - qui se consacrent, se passionnent ou se vouent à l'histoire de l'alimentation. 